\title{
On the speed of cocaine
}

\section{Roy A. Wise and Eugene A. Kiyatkin}

Brandon Aragona reasserts an argument that we questioned in our Perspective on the relative latencies of conditioned and unconditioned cocaine reward signals (Differentiating the rapid actions of cocaine. Nature Rev. Neurosci. 12, 479-484 (2011)) $)^{1}$ and reminds us of evidence that the conditioned and unconditioned signals seem to target different projection fields of the mesocorticolimbic (and nigrostriatal) dopamine systems (The regional specificity of rapid actions of cocaine. Nature Rev. Neurosci. 5 Oct 2011 (doi:10.1038/ nrn3043-c1 $)^{2}$. He is correct to suggest that the mesocorticolimbic dopamine system is heterogeneous and that the segments that are responsive to the unconditioned and conditioned effects of cocaine seem to be different. As he and others ${ }^{3}$ have noted, the projection to the shell of accumbens seems more responsive to cocaine itself, whereas the core of accumbens seems more responsive to cocaine-associated environmental cues.

In addition, recent studies have established subpopulations of dopamine neurons in the midbrain $^{4,5}$, including a subpopulation that co-expresses glutamate and a subpopulation that does not ${ }^{6}$. Our evidence for conditioned activation of dopamine neurons by peripheral cocaine cues involves measurements of dendritic dopamine release $\mathrm{e}^{7}$ and the firing rate of ventral tegmental area (VTA) dopamine neurons $^{8}$, and we did not attempt to differentiate between subsystems. It seems clear, however, that activation of subsystems that project to core and shell each contribute to the control of behaviour by cocaine ${ }^{9}$, and that the earliest of the two to elevate dopamine in the accumbens contributes first to cocaine reward.

We have two responses to the other points that are raised by Aragona. First, Aragona states that "recent voltammetry studies have measured real-time changes in dopamine concentration at the instant that cocaine enters the brain." The point of our article is that we do not know and cannot directly determine the instant when cocaine enters the brain, let alone the instant when it starts to block dopamine uptake or alter dopaminergic impulse flow. We have not ignored the indirect evidence from voltammetry studies; our article cites and discusses two of the four references indicated by Aragona, and we stand by our earlier comments on those papers (which apply equally to the others).

Second, Aragona argues that the primary (unconditioned) rewarding effect of cocaine is mediated by cocaine-induced dopamine release, not dopamine uptake blockade. However, he does not offer an explanation for the fact that nomifensine, a selective dopamine uptake inhibitor that lacks the major side-effects of cocaine, has (like cocaine itself) rewarding effects when locally injected into the ventral striatum ${ }^{10}$. Dopamine uptake inhibitors that are injected locally in this dopamine terminal field are unlikely to influence dopamine impulse flow. He also neglects to mention the recent evidence that cocaine is not rewarding in mice that lack the dopamine transporter ${ }^{11}$.

More importantly, Aragona offers no suggestion as to the mechanism that underlies the increased dopamine transients that he observes. Although similar transients are seen when dopamine autoreceptor function is blocked, does that necessarily mean that the release events caused by cocaine involve increased impulse flow? Could they not result from presynaptic control of dopamine release by glutamatergic input from the thalamus, prefrontal cortex, amygdala or hippocampus? And is it not possible that, whereas exteroceptive cocaine cues activate only the core of the accumbens, interoceptive cocaine cues may activate its shell as well? The effects of cocaine methiodide - which shares the peripheral but not the central effects of rewarding cocaine - have yet to be studied in the cocaine-trained animals that show conditioned glutamate input to the $\mathrm{VTA}^{7}$. As the direct effect of cocaine is to inhibit dopaminergic cell firing ${ }^{12,13}$, it will be important to identify the source of the dopamine transients that are seen in the voltammetric experiments of Aragona and colleagues ${ }^{14}$.

Clearly, much remains to be determined about the heterogeneity of function of the various dopamine subsystems. We hope that studies in this area will have direct relevance to the question of how quickly cocaine's direct and indirect actions on dopamine levels are felt in the various terminal fields of the mesocorticolimbic dopamine system (or systems).

Roy A. Wise and Eugene A. Kiyatkin are at the US National Institute on Drug Abuse, Behavioral Neuroscience Section, 251 Bayview Boulevard, Baltimore, Maryland 21224, USA.

Correspondence to R.A.W. e-mail: rwise@intra.nida.nih.gov doi:10.1038/nrn3043-c2 Published online 5 October 2011

Wise, R. A. $\&$ Kiyatkin, E. A. Differentiating the rapid actions of cocaine. Nature Rev. Neurosci. 12 , 479-484 (2011)

2. Aragona, B. The regional specificity of rapid actions of cocaine. Nature Rev. Neurosci. 5 Oct 2011 (doi: 10.1038/nrn3043-c1).

3. Ito, R., Dalley, J. W., Howes, S. R., Robbins, T. W. \& Everitt, B. J. Dissociation in conditioned dopamine release in the nucleus accumbens core and shell in response to cocaine cues and during cocaine-seeking behavior in rats. J. Neurosci. 20, 7489-7495 (2000).

4. Margolis, E. B., Mitchell, J. M., Ishikawa, J., Hjelmstad, G. O. \& Fields, H. L. Midbrain dopamine neurons: projection target determines action potential duration and dopamine $D(2)$ receptor inhibition. J. Neurosci. 28, 8908-1389 (2008).

5. Wang, H.-L. \& Morales, M. The corticotropin releasing factor binding protein (CRF-BP) within the ventral tegmental area is expressed in a subset of dopaminergic neurons. J. Comp. Neurol. 509, 302-318 (2008)

6. Yamaguchi, T., Wang, H. L., Li, X., Ng, T. H. \& Morales, M. Mesocorticolimbic glutamatergic pathway. J. Neurosci. 31, 8476-9084 (2011).

7. Wise, R. A., Wang, B. \& You, Z. B. Cocaine serves as a peripheral interoceptive conditioned stimulus for central glutamate and dopamine release. PLOS ONE 3 e2846 (2008).

8. Brown, P. L. \& Kiyatkin, E. A. Sensory effects of intravenous cocaine on dopamine and non-dopamine ventral tegmental neurons. Brain Res. 1218, 230-249 (2008)

9. Ito, R., Robbins, T. W. \& Everitt, B. J. Differential control over cocaine-seeking behavior by nucleus accumbens core and shell. Nature Neurosci. 7 389-397 (2004)

10. Carlezon, W. J., Devine, D. \& Wise, R. A. Habit-forming actions of nomifensine in nucleus accumbens. Psychopharmacology (Berlin) 122, 194-197 (1995).

11. Thomsen, J., Hall, F. S., Uhl, G. R. \& Caine, S. B. Dramatically decreased cocaine self-administration in dopamine but not serotonin transporter knock-out mice. J. Neurosci. 29, 1087-1092 (2009).

12. Einhorn, L. C., Johansen, P. A. \& White, F. J. Electrophysiological effects of cocaine in the mesoaccumbens dopamine system: Studies in the ventral tegmental area. J. Neurosci. 8, 100-112 (1988).

13. Kiyatkin, E. A., Kiyatkin, D. E. \& Rebec, G. V. Phasic inhibition of dopamine uptake in nucleus accumbens induced by intravenous cocaine in freely behaving rats. Neuroscience 98, 729-741 (2000).

14 Aragona, B. J., Cleaveland, N. A., Stuber, G. D., Day, J. J., Carelli R. M. \& Wightman, R. M. Preferential enhancement of dopamine transmission within the nucleus accumbens shell by cocaine is attributable to a direct increase in phasic dopamine release events. J. Neurosci. 28, 8821-8831 (2008). 